\title{
Volatility Clustering in Land Markets
}

\author{
Helen Xiaohui Bao ${ }^{\mathrm{a}}$, Hui Huang ${ }^{\mathrm{b}}$, Yu-lieh Huang ${ }^{\mathrm{c}}$, Pin-te Lin ${ }^{\mathrm{d}, 1}$ \\ ${ }^{a}$ Department of Land Economy, University of Cambridge, Cambridge, UK \\ ${ }^{\mathrm{b}}$ Faculty of Business Administration, University of Regina, Regina, Canada \\ ${ }^{ }$Department of Quantitative Finance, National Tsing Hua University, Hsinchu, Taiwan \\ ${ }^{\mathrm{d} S}$ Shool of Finance, Actuarial Studies and Applied Statistics, Australian National \\ University, Canberra, Australia
}

\begin{abstract}
This study is the first attempt to investigate the volatility clustering in the return of land markets. Using extensive monthly panel data at the provincial level from 1986 to 2013, we identify the existence of time-correlated and timevarying returns in Canadian land markets. Consistent with our proposed theory, volatility clustering in land markets tends to be observed in more populated areas. Our result has significant implications for portfolio management, economic theory and government policy by revealing the systematic pattern of volatility clustering in land markets.
\end{abstract}

${ }^{1}$ Corresponding author. E-mail: pinte.lin@anu.edu.au 


\section{Introduction}

Since the 2007-2009 Global Finance Crisis, the topic of volatility clustering in real estate markets has been extensively discussed. The existence of volatility clustering in property markets indicates that during certain periods, the conditional variance is much higher or lower than the unconditional variance; there is, therefore, a much higher risk of large losses for a process taking place during volatile periods than standard meanvariance analysis may suggest (Miles, 2008; Miao et al., 2011; Miles, 2011; Lin and Fuerst, 2013). Finding this existence of volatility clustering in property has important implications ranging from proper portfolio management to government policy (Miles, 2008; Miles, 2011; Lin and Fuerst, 2013).

First, comprehending this volatility pattern bears consequences for portfolio management as volatility in property prices has been found to be a constituent of mortgage default and prepayment (Foster and Van Order, 1984; Crawford and Rosenblatt, 1995; LaCour-Little et al., 2002; Miles, 2008; Miles, 2011). Second, the knowledge of property volatility clustering is of great interest to government officials through the channel of tax revenue since, for example, some state governments in the U.S. tax property directly or provide tax exemptions based on local property taxes (Miles, 2008).

Although volatility clustering in real estate markets has been widely analyzed since the 2007-2009 Global Financial Crisis, studies on this area merely focus on housing markets (see, for example, Miles, 2008; Lee, 2009; Miles, 2011; Miao et al., 2011; Lin and Fuerst, 2013). The literature on the volatility clustering in land markets, to the best of our knowledge, has never been explored. We believe that analyzing the volatility clustering patterns in land markets should be as important as housing markets since, after all, the values of property are in most cases mainly driven by the land values.

Therefore, the primary purpose of this study was to find the volatility clustering in land markets. Our study is the first attempt to explore this issue empirically and identifying volatility clustering, as previously mentioned, can shed insights on portfolio management and government policy. Moreover, in contrast to all of the previous literature on housing volatility clustering (such as Miles, 2008; Lee, 2009; Miao et al., 2011; Miles, 2011; Lin and Fuerst, 2013), our study builds a property theory to explain why we observe volatility clustering in land markets.

A case of Canadian land markets is preferably chosen in this study for several reasons. First, Canada is one of the few countries that publish the panel data of land value indices at the provincial level. Second, it is known that the majority of property indices tend to be limited in terms of their 
time series observations and the case of Canada offers us a rich panel observation of the monthly index from 1986 to 2013.

Most importantly, as argued in many studies (Knight et al., 2005; Hoesli and Lizieri, 2007; Lin and Fuerst, 2014), an ideal empirical analysis of property markets should depend on transaction-based rather than appraisal-based property indices since valuation-based property indices are unable to present the true returns of real estate markets. The advantage of using the land indices published by Statistics Canada circumvents these complications since they are transaction-based indices. With such an extensive and reliable dataset, Canadian land markets are, consequently, an ideal research area for empirical analysis.

Applying a Lagrange Multiplier (LM) test for AutoRegressive Conditional Heteroskedasticity (ARCH) effects in the Canadian land markets, we find that clustering in land price returns exists in Alberta, Ontario, Quebec, and British Columbia, which are the top four populated provinces in Canada. Taken together, these provinces account for approximately $86 \%$ of the country's population. This result is consistent with our proposed theory, suggesting that volatility clustering in land price returns should be found in more populated areas.

The outline of this paper is as follows. Section II describes the methodology. Section III presents the dataset and summary statistics. The discussion of empirical results is shown in Section IV. Section V concludes.

\section{Methodology}

\section{$L M$ tests for volatility clustering}

This study mainly explores the presence of volatility clustering in Canadian land markets at the province level through a Lagrange Multiplier (LM) test for AutoRegressive Conditional Heteroskedasticity (ARCH) effects proposed by Engle (1982):

$$
\begin{aligned}
& R_{t}=b_{0}+b_{1} R_{t-1}+\varepsilon_{t} \\
& \hat{\varepsilon}_{t}^{2}=C_{0}+\sum_{i=1}^{q} C_{i} \varepsilon_{t-1}^{2}+u_{t} \\
& L M=T * R^{2}
\end{aligned}
$$

where $R_{t}$ denotes the land returns (measured as the difference of the natural logarithms of the land value index) at time $t, u_{t}$ is a normally distributed disturbance term independent of $\varepsilon_{t} . T$ is the number of observations and $R^{2}$ is derived from Equation 2. The null hypothesis of LM 
test is that $\mathrm{H}_{0}: \mathrm{C}_{1}=\mathrm{C}_{2}=\mathrm{C}_{3}=\mathrm{C}_{4}=\ldots \mathrm{C}_{\mathrm{q}}=0$. The lag length of $\mathrm{q}$ chosen in the study is 60 , or the 5 year period. If $T * R^{2}$ exceeds the critical value of $X^{2}$, the null hypothesis of no ARCH effects can be rejected. Then, the series is found to display volatility clustering, which indicates that periods of high volatility will be followed by even higher volatility and vice versa.

\section{Data and Descriptive Statistics}

The monthly land price index for each individual province is obtained from Statistics Canada, covering all of the Canadian provinces (Alberta, Ontario, Quebec, Manitoba, Nova Scotia, Saskatchewan, New Brunswick, British Columbia, Prince Edward Island, as well as Newfoundland and Labrador).

Because of the lack of frequent transactions in direct real estate markets, property indices are inclined to be appraisal-based, which fails to seize market volatility and also carries more lagged information (Geltner, 1991 and 1993; Fisher et al., 1994; Chaplin, 1997; Cho et al., 2003; Booth and Marcato, 2004; Marcato and Key, 2007a and 2007b; Lizieri et al., 2012; Lin and Fuerst, 2014). The main advantage of applying the land value indices provided by Statistics Canada is that they are transaction-based indices, which avoid the potential problems in appraisal-based indices ${ }^{2}$.

The sample period for all of the provincial land markets is from January 1986 to October 2013. One exception is Prince Edward Island whose sample period can only be obtained from January 1995 to October 2013. The descriptive statistics of the land price returns in each province are summarised in Table 1.

Two important findings can be summarized here. Firstly, the number of our observations for each time series is quite sufficient, whose value is 333 for all of the provinces except for Prince Edward Island, whose number of observations is 225 . Still, this value is sufficient for time series analysis.

Secondly, the performance of land markets in each province may reflect its regional characteristics. The summary statistics show that the land markets in some provinces outperform those in other provinces in terms of risk-return relationships. For example, in Manitoba, the standard deviation of land returns is the highest at $1.60 \%$, but its return is not the highest. Similarly, the land price return of Alberta is the highest at $0.43 \%$, but its standard deviation is lower than Manitoba as well as Newfoundland and Labrador.

${ }^{2}$ The data is publicly available online at www.statcan.gc.ca. For further detailed description of the data, please refer to this website. 
Table 1. Descriptive Statistics of Land Price Returns

\begin{tabular}{lccccc}
\hline & $\begin{array}{c}\text { Mean } \\
(\%)\end{array}$ & $\begin{array}{c}\text { SD } \\
(\%)\end{array}$ & $\begin{array}{c}\text { Maximum } \\
(\%)\end{array}$ & $\begin{array}{c}\text { Minimum } \\
(\%)\end{array}$ & Count \\
\hline Alberta & 0.43 & 1.01 & 6.94 & -3.02 & 333 \\
Ontario & 0.22 & 0.88 & 5.36 & -3.21 & 333 \\
Quebec & 0.32 & 0.59 & 4.10 & -0.74 & 333 \\
Manitoba & 0.38 & 1.60 & 19.49 & -1.99 & 333 \\
Nova Scotia & 0.19 & 0.66 & 4.55 & -4.31 & 333 \\
Saskatchewan & 0.35 & 0.87 & 7.00 & -0.91 & 333 \\
New Brunswick & 0.17 & 0.78 & 8.70 & -2.90 & 333 \\
British Columbia & 0.21 & 0.96 & 5.67 & -5.12 & 333 \\
Prince Edward Island & 0.21 & 0.68 & 6.42 & -1.41 & 225 \\
Newfoundland and Labrador & 0.30 & 1.06 & 8.37 & -3.54 & 333 \\
\hline Not The
\end{tabular}

Note: The returns are calculated as: $r_{t}=\ln \left(P_{t} / P_{t-1}\right)$ where $P_{t}$ is the price index at time $t$.

\section{Results and Discussion}

\section{Empirical Results}

Table 2 presents the results of volatility clustering in Canadian land markets. The results of the Lagrange Multiplier (LM) test reveal that volatility clustering exists in Alberta, Ontario, Quebec, and British Columbia. The volatility clustering in these areas suggests that practitioners and policy makers should be concerned with the probability of larger losses in the returns of land markets during volatile periods than the standard-mean variance analysis indicates. As a result, financial modelling of volatility clustering should be taken into consideration (Miles, 2008; Lee, 2009; Miles, 2011; Lin and Fuerst, 2013).

Table 2. Volatility Clustering of Land Price Returns

\begin{tabular}{|c|c|c|c|c|}
\hline & \multicolumn{2}{|c|}{$\operatorname{AR}(1)$} & LM Test & $\begin{array}{c}\text { Population } \\
\text { Rank }\end{array}$ \\
\hline & $b_{0}$ & $b_{1}$ & & \\
\hline Alberta & $0.001^{* * *}$ & $0.59 * * *$ & $90.43^{* * *}$ & 4 \\
\hline Ontario & $0.0008^{* *}$ & $0.610^{* * *} *$ & $87.63 * * *$ & 1 \\
\hline Quebec & $0.002^{* * *}$ & $0.133 * * *$ & $83.38 * *$ & 2 \\
\hline Manitoba & $0.002^{* * *}$ & $0.28^{* * *}$ & 20.17 & 5 \\
\hline Nova Scotia & $0.001 * * *$ & 0.026 & 42.99 & 7 \\
\hline Saskatchewan & $0.002^{* * *}$ & $0.21 * * *$ & 75.83 & 6 \\
\hline New Brunswick & $0.002^{* * *}$ & -0.018 & 36.09 & 8 \\
\hline British Columbia & $0.001 * * *$ & $0.38^{* * *}$ & $134.75^{* * *}$ & 3 \\
\hline Prince Edward Island & $0.002^{* * *}$ & -0.029 & 10.02 & 10 \\
\hline Newfoundland and Labrador & $0.002^{* * *}$ & 0.082 & 52.16 & 9 \\
\hline
\end{tabular}

Notes: *** and ** indicate significance at the 0.01 and 0.05 levels, respectively. See Section II for details of corresponding parameter estimates. The rank of population is based on the 2011 Census of Canada. 


\section{Discussion of Results}

Following previous studies in this field (e.g., Miles, 2008; Lee, 2009; Miles, 2011; Miao et al., 2011; Lin and Fuerst, 2013), we have applied a Lagrange Multiplier (LM) test for the AutoRegressive Conditional Heteroskedasticity $(\mathrm{ARCH})$ effects in property markets, particularly in the field of land markets. Along with the previous literature, the results we obtain here are just econometric outcomes and the reasons why we observe volatility clustering are not sufficiently explained in the previous literature. Thus, we are convinced that even though using an econometric method to identify volatility clustering is important, establishing a theory to explain why we observe volatility clustering in some markets but not in others is in fact more significant.

The definition of volatility clustering is that large returns are expected to follow large returns, and small returns to follow small returns (Mandelbrot, 1963). Such a phenomenon is observed because various sources of news and other exogenous economic events have a persistent impact on the time series pattern of asset prices (Franses, 1998). In fact, since the development of the Lagrange Multiplier (LM) test for the AutoRegressive Conditional Heteroskedasticity (ARCH) effects, volatility clustering in stock markets is always found. Recent studies (e.g., Miles, 2008; Lee, 2009; Miao et al., 2011; Miles, 2011; Lin and Fuerst, 2013) shift their attention from stock to property markets, yet finding that in contrast to stock markets, volatility clustering is sometimes observed in some property markets but not in others.

Lin and Fuerst (2014) argue that stock and direct real estate markets should hypothetically be related to their economic fundamentals, but the unique unfavourable features of property as an asset -high transaction cost, illiquidity, large lot size and information asymmetry -cause the real estate markets to behave differently from equity markets. Their empirical evidence suggests that real estate markets in more densely populated areas behave more like stock markets. They build a theory that densely populated real estate markets will be more efficient since markets in these areas have more frequent transactions, and as such, this market will be more transparent and liquid as well as less sluggish with fewer transaction and information costs.

Summarizing the theoretical argument of Franses (1998) and Lin and Fuerst (2014), we can reach the conclusion that different sources of news and other exogenous shocks have persistent influence on asset prices, yet this impact can be sufficiently transmitted in the more efficient financial markets. This argument helps us understand why volatility clustering is always observed in the literature of stock markets, but in some cases not 
observed in the recent literature of real estate markets.

Using population as the proxy for efficient markets, we do find evidence to support such a theoretical statement. In our sample of ten Canadian provinces, only the top four provinces with the highest population (Alberta, Ontario, Quebec, and British Columbia) have volatility clustering in their land markets, whereas the other six provinces with lower population do not possess time-correlated and time-varying returns in their land markets. Our study does not imply that various news and economic events do not have an impact on the land price returns in less populated areas, but suggest that such an influence in this area will be more transitory. After all, information is transmitted among its residents and less populated areas have less information carriers (Lin and Fuerst, 2013).

\section{Conclusion}

In the wake of the recent Global Financial Crisis, there have been increasing interests in appropriately ascertaining the probability of large losses on property prices. Complimenting previous studies on housing volatility clustering (Miles, 2008; Lee, 2009; Miao et al., 2011; Miles, 2011; Lin and Fuerst, 2013), we have focused on the land markets. Through using a transaction-based monthly dataset from 1986 to 2013, we disclose timecorrelated and time-varying returns in the provincial land markets of Canada.

Real estate theory suggests that clustering in land price volatility should be observed in more highly populated areas. Our empirical evidence offers support to this argument by showing that volatility clustering is observed in the four most highly populated provinces of Canada (Alberta, Ontario, Quebec, and British Columbia).

Since our study is the first attempt in this area, a natural next step is to examine whether our proposed theory can be robustly applied to other countries and also to locate the possible determinants of clustering in land prices. We leave this interesting topic for future research. 


\section{References}

Booth, P. and Marcato, G. (2004) The measurement and modelling of commercial real estate performance, British Actuarial Journal, 10, 5-61.

Chaplin, R. (1997) Unsmoothing valuation-based indices using multiple regimes, Journal of Property Research, 14, 189-210.

Cho, H., Kawaguchi, Y. and Shilling, D. J. (2003) Unsmoothing commercial property returns: a revision to Fisher-Geltner-Webb's unsmoothing methodology, Journal of Real Estate Finance and Economics, 27, 393-405.

Crawford, G. and Fratantoni, M. (2003) Assessing the forecasting performance of regime-switching, ARIMA and GARCH models of house prices, Real Estate Economics, 31, 223-43.

Engle, R. F. (1982) Autoregressive conditional heteroscedasticity with estimates of the variance of United Kingdom inflation, Econometrica, 50, 987-1008.

Fisher, J. D., Geltner, D. M. and Webb, R. B. (1994) Value indices of commercial real estate: a comparison of index construction methods, Journal of Real Estate Finance and Economics, 9, 137-64.

Foster, C. and Van Order, R. (1984) FHA terminations: A prelude to rational mortgage pricing, Journal of the American Real Estate and Urban Economics Association, 13, 27391.

Geltner, D. (1991) Smoothing in appraisal-based returns, Journal of Real Estate Finance and Economics, 4, 327-45.

Geltner, D. (1993) Estimating market values from appraised values without assuming an efficient market, Journal of Real Estate Research, 8, 325-45.

Hoesli, M. and Lizieri, C., 2007. Real estate in the investment portfolio. A Report Prepared for the Investment Strategy Council of the Royal Ministry of Finance: Norway, May.

Knight, J., Lizieri, C., and Satchell, S., (2005) Diversification when It hurts? The joint distributions of real estate and equity markets. Journal of Property Research, 22, 309-323.

LaCour-Little, M., Marschoun, M. and Maxam C. (2002) Improving parametric mortgage prepayment models with non-parametric kernel regression, Journal of Real Estate Research, 24, 299-328.

Lee, C. L. (2009) Housing price volatility and its determinants, International Journal of Housing Markets and Analysis, 2, 293-308.

Lizieri, C., Satchell, S. and Wongwachara, W. (2012) Unsmoothing real estate returns: a regime-switching approach, Real Estate Economics, 40, 775-807.

Lin, P, and Fuerst, F. (2013) Volatility clustering, risk-return relationship and asymmetric adjustment in Canadian housing markets, Working Paper.

Lin, P, and Fuerst, F. (2014) The integration of direct real estate and stock markets in Asia, Applied Economics, 46, 1323-1334.

Mandelbrot, B. B. (1963) The variation of certain speculative prices, Journal of Business, 40, 392-417.

Marcato, G. and Key, T. (2007a) Index smoothing and the volatility of commercial property, Technical Report, Investment Property Forum: London.

Marcato, G. and Key, T. (2007b) Smoothing and implication for asset allocation choices, Journal of Portfolio Management, 33, 85-99.

Miao, H., Ramchander, S. and Simpson, M. W. (2011) Return and volatility transmission in U.S. housing markets, Real Estate Economics, 39, 701-41.

Miles, W. (2008) Volatility clustering in U.S. home prices, Journal of Real Estate Research, 30, 74-90. 
Miles, W. (2011) Clustering in U.K. home price volatility, Journal of Housing Research, 20, 87-101. 